\title{
PROCESS OF OBTAINING BIOETHANOL FROM SORGHUM BIOMASS USING GENOME SHUFFLING
}

\author{
JOLANTA BATOG and ALEKSANDRA WAWRO \\ Institute of Natural Fibres and Medicinal Plants, Wojska Polskiego 71b, 60-630 Poznan, Poland \\ \Corresponding author: Jolanta Batog, jolanta.batog@iwnirz.pl
}

Received January 31, 2019

\begin{abstract}
One of the materials to be used for the production of bioethanol might be sorghum, an alternative plant for bioenergy production. In the process of obtaining biofuels, the bioprocess technology is as important as the plant material. The production of bioethanol from lignocellulosic materials requires degrading cell walls to specific polymers and the hydrolysis of carbohydrates to monomer sugars.

The aim of the study was to evaluate the chemical and enzymatic treatment of sorghum biomass during the preparation of the material for the production of ethanol. Biomass processing consists in the disintegration of the solid phase and breaking down of compact lignocellulose. The highest content of glucose was obtained using enzymatic hydrolysis with cellulolytic enzyme, i.e. Flashzyme Plus 200. After genome shuffling, the distillery yeast demonstrated an increased fermentation activity and resistance to environmental stress factors formed during the process of ethanol production.
\end{abstract}

Keywords: bioethanol, sorghum biomass, pretreatment, genome shuffling

\section{INTRODUCTION}

Biofuels constitute a favourable choice for fuel consumption due to their renewability, biodegradability and generation of acceptable quality exhaust gases. ${ }^{1}$ Bioethanol produced from organic raw materials is a renewable and clean resource for energy production, which is used as fuel, as well as in the chemical, cosmetic and pharmaceutical industries. Some plants that can be used for bioenergy production are, for example, sorghum and miscanthus, as their high calorific value of combustion and high yield of dry biomass make them suitable materials for the production of $2^{\text {nd }}$ generation biofuels.

Sorghum is an annual plant that can reach the height of $4 \mathrm{~m}$. It is tolerant to drought, contains high amounts of monosaccharides (approx. 10\%) and provides high yields of dry mass $\left(28 \mathrm{t} \cdot \mathrm{ha}^{-1}\right)$ at the so-called milk-wax phase of the seed. ${ }^{2,3}$ The energetic value of combustion of sorghum is 15 $\mathrm{MJ} \cdot \mathrm{kg}^{-1}$.

Lignocellulosic biomass is characterized by the complexity of its chemical composition, as its structure contains a polymeric complex called lignocellulose, which is relatively difficult to biodegrade. Lignin, structurally crosslinked by ester and carbon bonds, is an effective obstacle in the production of bioethanol from plant biomass. Lignin and its derivatives have a negative effect on the hydrolysis of biomass, as they physically hinder the access of cellulases to the microfibrils of crystalline cellulose and also bind cellulases and lead to their deactivation. ${ }^{4-9}$

The production of biofuel from lignocellulosic material requires the deconstruction of the cell wall into individual polymers and the hydrolysis of carbohydrates into monomeric sugars. This requires subjecting the biomass to pretreatment, which affects significantly the course of the further stages of bioethanol production, i.e. the enzymatic hydrolysis and fermentation process, as well as decides on the final efficiency of the process. ${ }^{10-11}$ In order to disintegrate the biomass and remove lignin, several pretreatment methods have been tested - physical, chemical and biological ones. ${ }^{12-15}$ The physical pretreatment methods of lignocellulosic biomass, which aim to reduce the size of the substrate, as well as to facilitate the access of bioactive substances to the surface, reducing polymerization and the crystallization degree of lignocellulose, include: milling, an extrusion method and an ultrasonic pretreatment. ${ }^{16-17}$ The chemical processes include 
acid (sulfuric, hydrochloric acid), alkali (sodium hydroxide, calcium carbonate, ammonia) and neutral (ionic liquids) treatments, the organosolv process, the ammonia fibre explosion and ozonolysis. ${ }^{18-19}$ Depending on the method used, different changes occur within the lignocellulosic complex. The alkali pretreatment has mainly the function of delignification, while the acid pretreatment process dissolves most hemicellulose. The non-specificity of the acidic treatment leads to the formation of complex sugars and compounds that inhibit the activity of the microorganisms utilized for ethanol production. ${ }^{20}$ An effective pretreatment process should possess the following advantages: it should preserve and decrystallize the cellulose, depolymerize the hemicellulose, restrict the formation of inhibitors, require low energy input, allow recovering value-added products, such as lignin, and, finally, it should be cost-effective. ${ }^{21}$

Next, it is important that the simple sugars obtained in the enzymatic hydrolysis be available to the distillery yeast in the fermentation process. The synergistic action of enzymes in the process of hydrolysis involves the attack on the cellulose by bonding with cellulose fibres in amorphous places, the cleavage of cellulosic chains, cutting off their considerable fragments, and then degrading them until the glucose polymer is obtained.

Furthermore, the Saccharomyces cerevisiae distillery yeast is most popular for the production of biofuels from lignocellulosic biomass. However, the economic aspect is challenged by the decreased fermentation performance of the yeast in the presence of various environmental stress factors, such as high temperature or toxins. Most distillery yeasts used in bioethanol production have the optimum temperature of 30$35^{\circ} \mathrm{C} .{ }^{22-23}$ Raw lignocellulosic materials are often pretreated at about $200{ }^{\circ} \mathrm{C}$, during which various toxins are formed. ${ }^{24}$ The commercially available cellulases and hemicellulases carry out the hydrolysis efficiently at temperatures in the range of $45-50{ }^{\circ} \mathrm{C}$. Therefore, improving the resistance of distillery yeast to environmental stress factors is critical for achieving an efficient and economically viable bioconversion of cellulose to biofuels. $^{25}$

Currently, genome shuffling is one of the most important tools of improving the industrial properties of microorganisms. This method involves combining several parental strains, each of which has at least one beneficial technological trait, into a hybrid. These traits can be accumulated by using several rounds. ${ }^{26}$ The first step in the construction of new hybrids is to create a parental library, using random mutagenesis and rapid screening. ${ }^{27}$ This way, a parental library with strong resistance properties is created. These strains are then subjected to the protoplastization and further combined in the protoplast fusion. After each round, it is necessary to conduct a fusant screening to select the best strains. ${ }^{26,28}$

\section{EXPERIMENTAL}

\section{Materials and methods}

The raw material used in the study was Sucrosorgo 506 biomass from the Experimental Farm of INF\&MP in Sielec Stary, Poland. The raw material was subjected to preliminary crushing to particles of 2-4 $\mathrm{cm}$ in size and then dried at $50-55{ }^{\circ} \mathrm{C}$ for $24 \mathrm{~h}$. Next, the material was disintegrated in a knife mill (Retsch SM-200, Germany) with a sieve of $4 \mathrm{~mm}$ mesh size.

To optimize the enzymatic hydrolysis, the Flashzyme Plus 200 enzymatic preparation from AB Enzymes was used, which consists of endoglucanase, cellobiohydrolase, cellobiase, xylanase and mannanase. The cellulolytic activity of Flashzyme determined according to the method of Adney and Baker (2008) ${ }^{29}$ was $123 \mathrm{FPU} \cdot \mathrm{mL}^{-1}$ and the xylanolytic activity according to the Osaka University procedure was $2666 \mathrm{XU} \cdot \mathrm{mL}^{-1}$. 30

Saccharomyces cerevisiae yeast (commercial strain Ethanol Red) was obtained from Lessafre Fermentis, France. The microorganisms were stored on Yeast extract Peptone Dextrose (YPD) medium with the addition of $1 \%$ yeast extract $(w / v), 2 \%$ peptone $(w / v), 2 \%$ glucose $(w / v)$ and $2 \%(w / v)$ agar-agar kept at the temperature of 4-8 ${ }^{\circ} \mathrm{C}$.

The effect of the chemical processing of sorghum biomass was determined for sulfuric acid after a 10minute treatment with $2 \%$ acid and after autoclaving at $121{ }^{\circ} \mathrm{C}$ for $1 \mathrm{~h}$, while for sodium hydroxide after $5 \mathrm{~h}$ treatment with $1.5 \%$ alkali at $90{ }^{\circ} \mathrm{C}$.

The effect of sulfuric acid and sodium hydroxide on the content of the released reducing sugars was evaluated by Miller's method (1959) ${ }^{31}$ with 3,5dinitrosalicylic acid (DNS) in the enzymatic test. The test was performed with the use of the Celluclast $1.5 \mathrm{~L}$ (Novozymes) enzymatic preparation in the dose of 10 FPU $\cdot \mathrm{g}^{-1}$. The raw material was incubated at $55{ }^{\circ} \mathrm{C}$ in $0.05 \mathrm{M}$ citrate buffer of $\mathrm{pH} 4.8$ for $24 \mathrm{~h}$. Then, the absorbance measurement was carried out against the reference sample at the wavelength of $530 \mathrm{~nm}$ (UVVIS Spectrophotometer, Jasco V-630, Germany).

The optimization of the enzymatic hydrolysis of sorghum biomass was carried out according to the Response Surface Methodology (RSM), using the following parameters: biomass content $5-10 \%$, 
temperature $50-70{ }^{\circ} \mathrm{C}$, time $24-72 \mathrm{~h}, \mathrm{pH} 4.2-5.4$, dose of Flashzyme 10-30 FPU. $\mathrm{g}^{-1}$.

The content of glucose was determined by High Performance Liquid Chromatography (HPLC, Agilent Technologies 1200, Germany).

To construct the parental library for genome shuffling, chemical mutagenesis using ethylmethanesulfonate (EMS) was carried out. The obtained mutants were subjected to the protoplastization process with $2 \%(w / v)$ Glucanex (Sigma-Aldrich). The protoplastization of the yeast mutant was carried out on $1 \mathrm{~g}$ for $75 \mathrm{~min}$ at $30{ }^{\circ} \mathrm{C}$ in a thermomixer (Eppendorf), with continuous stirring. The protoplast fusion was performed using $40 \%(\mathrm{w} / \mathrm{v})$ polyethylene glycol (PEG). The protoplasts were then regenerated $\left(0.6 \mathrm{M} \mathrm{KCL}\right.$ and $\left.0.01 \mathrm{M} \mathrm{CaCl}_{2}\right)$ and screened for fermentation activity, thermotolerance, osmotolerance and resistance to acetic acid. The best strains after the mutagenesis (M) and screening were selected to be the parental strains for the protoplast fusion $(F)$. The new strains were again regenerated and screened for the fermentation activity, thermotolerance, osmotolerance and resistance to acetic acid.

The sorghum biomass after the pretreatment and enzymatic hydrolysis was sterilized by autoclaving at $121{ }^{\circ} \mathrm{C}$ for $15 \mathrm{~min}$ and was used as fermentation medium. The medium was inoculated with $S$. cerevisiae cells from the inoculum culture $(10 \% \mathrm{v} / \mathrm{v})$. The fermentation process was carried out in a $250 \mathrm{~mL}$ Erlenmeyer flask incubated in a rotary shaker at 140 $\mathrm{rpm}$ for $72 \mathrm{~h}$ at $37{ }^{\circ} \mathrm{C}$ and $\mathrm{pH}$ 4.8. Additionally, a fermentation process using the yeast improved by the genome shuffling method was carried out. This process was performed in a $250 \mathrm{~mL}$ Erlenmeyer flask incubated in a rotary shaker at $140 \mathrm{rpm}$ for $72 \mathrm{~h}$ at 37 ${ }^{\circ} \mathrm{C}$, with the addition $0.1 \%(\mathrm{v} / \mathrm{v})$ acetic acid at $\mathrm{pH} 4.8$. After the fermentation process, the concentration of ethanol was determined by HPLC.

\section{Analytical methods}

The chemical components of sorghum biomass were evaluated as follows: cellulose according to TAPPI T17 m-55, hemicellulose as the difference between holocellulose (according to TAPPI T9 m-54) and cellulose, and lignin according to TAPPI T13 m54. ${ }^{32-34}$ The chemical composition was also determined in the solid fraction formed after the chemical treatment, while for the liquid phase after acidic treatment, toxins (furfural, hydroxymethylfurfural, acetic acid) and pentoses (xylose, arabinose) were determined using an Agilent Technologies 1200 HPLC Chromatograph, with a DAD detector for toxins and an RID detector for pentoses.

The analysis of FTIR spectra was conducted on the sorghum biomass before and after the chemical treatment, using a Fourier Transform Infrared Spectrometer (FTIR, Bruker ISS 66v/S, Germany) at infrared wavelengths of $400-4000 \mathrm{~cm}^{-1}$.
The images of sorghum biomass before the process, after the chemical treatment and enzymatic hydrolysis were acquired by using a Scanning Electron Microscope (SEM, S-3400N, Hitachi, JPN) in high vacuum conditions. The samples were sputtered with gold.

The random amplified polymorphic DNA (RAPD) analysis was carried out to detect the genetic difference between the parental strains and the fusants after genome shuffling using random prime RAPD_21(GCTCGTCGCT). The DNA was isolated from the strains using Genomic Mini AX Yeast (A\&A Biotechnology, Gdynia, Poland) by a procedure presented by the manufacturer. The Polymerase Chain Reaction (PCR) method was performed in a buffer (25 $\mu \mathrm{L}$ ) in a Veriti Thermal Cycler (Applied Biosystems) with the following temperature profiles: the initial denaturation at $95{ }^{\circ} \mathrm{C}$ for $5 \mathrm{~min}, 35$ cycles of denaturation at $95{ }^{\circ} \mathrm{C}$ for $30 \mathrm{~s}$, the primer annealing at $36{ }^{\circ} \mathrm{C}$ for $45 \mathrm{~s}$, the extension at $72{ }^{\circ} \mathrm{C}$ for $1.5 \mathrm{~min}$ and the final cycle of extension in $72{ }^{\circ} \mathrm{C}$ for $3 \mathrm{~min}$, then the reaction was held at $4{ }^{\circ} \mathrm{C}$. The PCR products were resolved by electrophoresis on $1 \%$ agarose gel containing ethidium bromide, visualized under a UV illuminator. GeneRuler Express (Thermo Fisher Scientific) was used as a marker.

\section{RESULTS AND DISCUSSION}

The success of using renewable biomass for ethanol production depends on the physical and chemical properties of the biomass, the pretreatment methods, efficient microorganisms and the optimization of the processing conditions. The primary goal of the chemical pretreatment is to improve the cellulose biodegradability by removing lignin and/or hemicellulose, and, to a lesser extent, to reduce the polymerization degree (PD) and crystallinity of the cellulose component. An efficient pretreatment method is required for the enzymatic hydrolysis to yield maximum sugar productivity.

Two types of pretreatment were compared, i.e. acidic treatment with $2 \%$ sulfuric acid $(10 \mathrm{~min})$ and autoclaving process $\left(121{ }^{\circ} \mathrm{C}, 1 \mathrm{~h}\right)$, and alkaline treatment with $1.5 \%$ sodium hydroxide $\left(90{ }^{\circ} \mathrm{C}, 5 \mathrm{~h}\right)$, which were conducted on sorghum biomass ground on a knife mill and sieved on a mesh size of $4 \mathrm{~mm}$. In order to determine the efficiency of chemical processing of the sorghum biomass, the content of reducing sugar was measured by Miller's method in the enzymatic test. The results allow concluding that the sodium hydroxide pretreatment is a more efficient method for sorghum biomass, compared to the pretreatment with sulfuric acid. The content of 
reducing sugar was $577 \mathrm{mg} \cdot \mathrm{g}^{-1}$ and $212 \mathrm{mg} \cdot \mathrm{g}^{-1}$, respectively.

The action mode of dilute acid is to solubilize hemicellulose and leave lignin and cellulose intact, so that the enzymatic digestibility of cellulose is enhanced. The alkaline pretreatment involves basically a delignification process, in which a significant amount of hemicellulose is also solubilized. In comparison with other pretreatment technologies, the alkali pretreatment usually needs lower temperatures and pressures. The pretreatment time, however, lasts a few hours, which is much longer than the time required for other pretreatment processes. ${ }^{35}$

Table 1 presents the chemical composition (cellulose, hemicellulose, lignin) of the sorghum biomass before and after the chemical pretreatment (in the solid fraction) with sulfuric acid and sodium hydroxide. The chemical composition confirmed that the alkaline treatment consists mainly in delignification, whereas the acid treatment dissolves most hemicellulose.

The acidic treatment offers good performance, in terms of recovering hemicellulose sugars (especially pentoses in the liquid phase), but it also has some drawbacks. The hemicellulose sugars might be further degraded to furfural and hydroxymethylfurfural (HMF), strong inhibitors of microbial fermentation. The content of pentoses and toxins in the liquid phase, after the acidic treatment of sorghum biomass, was for xylose $9.53 \mathrm{~g} \cdot \mathrm{L}^{-1}$, arabinose $1.08 \mathrm{~g} \cdot \mathrm{L}^{-1}$, furfural $0.18 \mathrm{~g} \cdot \mathrm{L}^{-1}, \mathrm{HMF} 0.28 \mathrm{~g} \cdot \mathrm{L}^{-1}$, and acetic acid 1.44 $\mathrm{g} \cdot \mathrm{L}^{-1}$. In the case of the alkaline treatment, due to its mild conditions, the degradation of sugars to furfural, HMF and organic acids is limited. An ideal pretreatment technique should be able to maximize the recovery of available carbohydrates, such as cellulose and hemicellulose, while minimizing the degradation of sugars and the generation of possible inhibitors.

The next stage of converting biomass to bioethanol is the enzymatic hydrolysis process that determines what amount of simple sugars can be metabolized by the yeast in the ethanol fermentation process. After the alkaline pretreatment of sorghum biomass with sodium hydroxide, the enzymatic hydrolysis process was performed. The highest content of glucose released according to the response surface method (Fig. 1) was obtained using the following parameters: $50{ }^{\circ} \mathrm{C}, \mathrm{pH} 4.2,72 \mathrm{~h}$, for $10 \%$ sorghum biomass and $30 \mathrm{FPU} \cdot \mathrm{g}^{-1}$ Flashzyme.

Table 1

Chemical composition of sorghum biomass

\begin{tabular}{lccc}
\hline Sample & Cellulose $(\%)$ & Hemicellulose $(\%)$ & Lignin $(\%)$ \\
\hline BP & $29.87 \pm 0.51$ & $29.03 \pm 0.29$ & $21.74 \pm 0.39$ \\
ACP & $59.18 \pm 1.92$ & $8.21 \pm 0.06$ & $28.62 \pm 0.35$ \\
ALP & $47.34 \pm 0.22$ & $28.40 \pm 0.12$ & $9.19 \pm 0.44$
\end{tabular}

BP: before pretreatment; ACP: acidic pretreatment; ALP: alkaline pretreatment

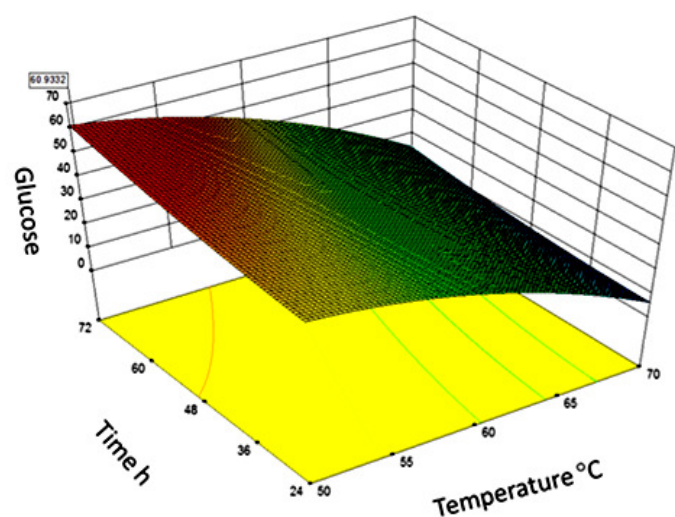

Figure 1: Enzymatic hydrolysis process of sorghum biomass (RSM) 
Table 2

Characteristic infrared absorption bands

\begin{tabular}{lcc}
\hline Band & Compound type & Band range $\left(\mathrm{cm}^{-1}\right)$ \\
\hline C-H stretching vibrations & aromatic rings & $2800-3000$ \\
C-H stretching vibrations & aldehydes and ketones & 2720 \\
C-H bending vibrations (in-plane) & aromatic rings & $1000-1100$ \\
C-H bending vibrations (off-plane) & aromatic rings & $675-870$ \\
C-H bending vibrations & methyl group - $\mathrm{CH}_{3}$ & $1430-1470,1375$ \\
C-C stretching vibrations & methylene group - $\mathrm{CH}_{2}-$ & $1430-1470$ \\
C-C stretching vibrations & aromatic rings & $1500-1600$ \\
C-C stretching vibrations & guaiacyl ring & 1270 \\
C-O stretching vibrations & syringyl ring & 1330 \\
& phenols & $1140-1230$ \\
C=O stretching vibrations & carboxylic acids & 1250 \\
& aldehydes and ketones & $1675-1725$ \\
O-H stretching vibrations & carboxylic acids & $1680-1725$ \\
O-H bending vibrations & phenols & $3200-3600$ \\
\hline
\end{tabular}

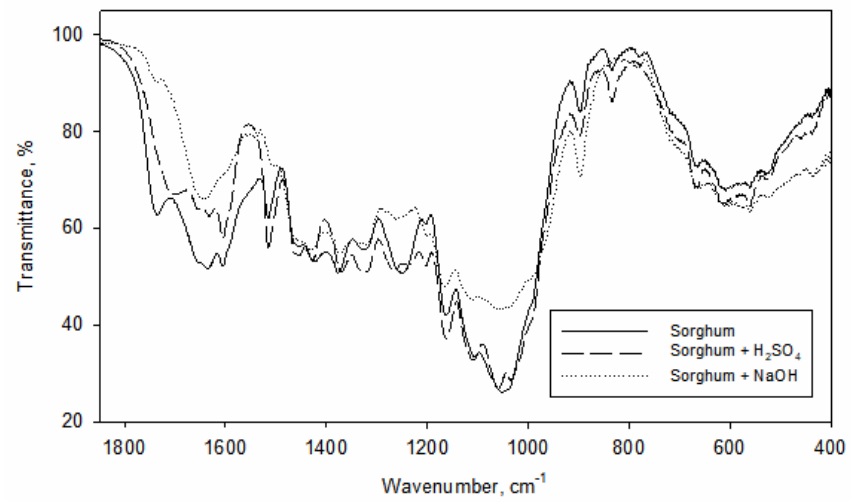

Figure 2: FTIR spectra of sorghum biomass before and after chemical treatment

The measurements of light absorption within the infrared spectrum are of high importance in studying the structure of chemical substances, as they help determine the functional groups and the location as well as the types of bonding. The absorption spectrum is characteristic of a given compound and, therefore, can be used for identification. Specific atom groups cause the formation of characteristic absorption bands, i.e. they absorb the radiation of precise frequency, to a large extent irrespective of the type of compound that they are found in. The absorption of radiation triggers vibrations within molecules. The frequency of the vibrations of several groups found in organic compounds and lignin are shown in Table 2. . $^{36-38}$

The spectra of untreated sorghum biomass are presented in Figure 2, along with those of the biomass pretreated with sulfuric acid and sodium hydroxide. ${ }^{39}$ Comparing the FTIR spectra of the untreated and pretreated biomass, as regards the transmittance at $1730 \mathrm{~cm}^{-1}(\mathrm{C}=\mathrm{O}$ of carbonyl group), $1510 \mathrm{~cm}^{-1}$ (C-C of aromatic ring) and $1270 \mathrm{~cm}^{-1}$ (C-O of guaiacyl ring), it may be concluded that the spectra indicate the delignification of sorghum biomass, especially after the treatment with sodium hydroxide. It may be also observed that there exists an increase in the band intensity at $898 \mathrm{~cm}^{-1}$ and a decrease at $1427 \mathrm{~cm}^{-1}$, which indicates lower crystallinity and an increase of the amorphous form of cellulose as a result of chemical pretreatments, in particular, of the alkaline treatment. ${ }^{40}$

The morphological features of sorghum biomass before and after the pretreatment and enzymatic hydrolysis are shown in Figure 3. The untreated sorghum biomass was observed to have a sedimentary layer on the surface area. ${ }^{41}$ This 
layer can include waxes, hemicellulose, lignin or other bonding materials. ${ }^{42}$ The SEM images of the biomass after the chemical pretreatment showed prominent roughness and looser structure, as compared to the untreated sample, making the fibres more vulnerable to the enzymatic hydrolysis. ${ }^{41}$ The surface layer was removed during the pretreatment, resulting in the exposure of the internal structure and the fibres. During the enzymatic hydrolysis, the external surface of sorghum biomass was damaged and further removal of the external surface, exposing the internal structure, can be observed.

Ten mutants with improved resistance to high temperature and toxins were obtained from populations generated by chemical mutagenesis using EMS. On the basis of the results of the screening tests, a parental library consisting of 4 mutants was created (M1, M2, M3, M4). The stage of constructing the parental strains library using the mutagenesis process is extremely important, as it allows the generation of a larger number of genotypes, which, in turn, influences the final effect of genome shuffling. ${ }^{23,43}$ These yeast strains were then subjected to recursive protoplast fusion. After two rounds of genome shuffling, the best performing fusant (MF3) was obtained. It is characterized by better growth and about $40 \%$ higher ethanol productivity than the initial strains (Fig. 4). This is an excellent achievement, because according to other authors, after two rounds of genome shuffling, it was possible to receive a strain characterized by over $20 \%$ higher ethanol productivity. ${ }^{44-46}$

After the fermentation process with Saccharomyces cerevisiae, a 30\% higher concentration of ethanol was observed for the samples inoculated with the yeast improved by the genome shuffling method. The maximum value of ethanol concentration was achieved after $72 \mathrm{~h}$ for both initial strains $\left(19.02 \mathrm{~g} \cdot \mathrm{L}^{-1}\right)$ and fusant MF3 (49.88 $\left.\mathrm{g} \cdot \mathrm{L}^{-1}\right)$. It can therefore be inferred that improved fusants are characterized by increased tolerance to temperature and toxins that occur during the pretreatment of lignocellulosic biomass. ${ }^{47}$ These strains are also important for the industry, as they can contribute to lowering the costs of bioethanol production. ${ }^{48,49}$

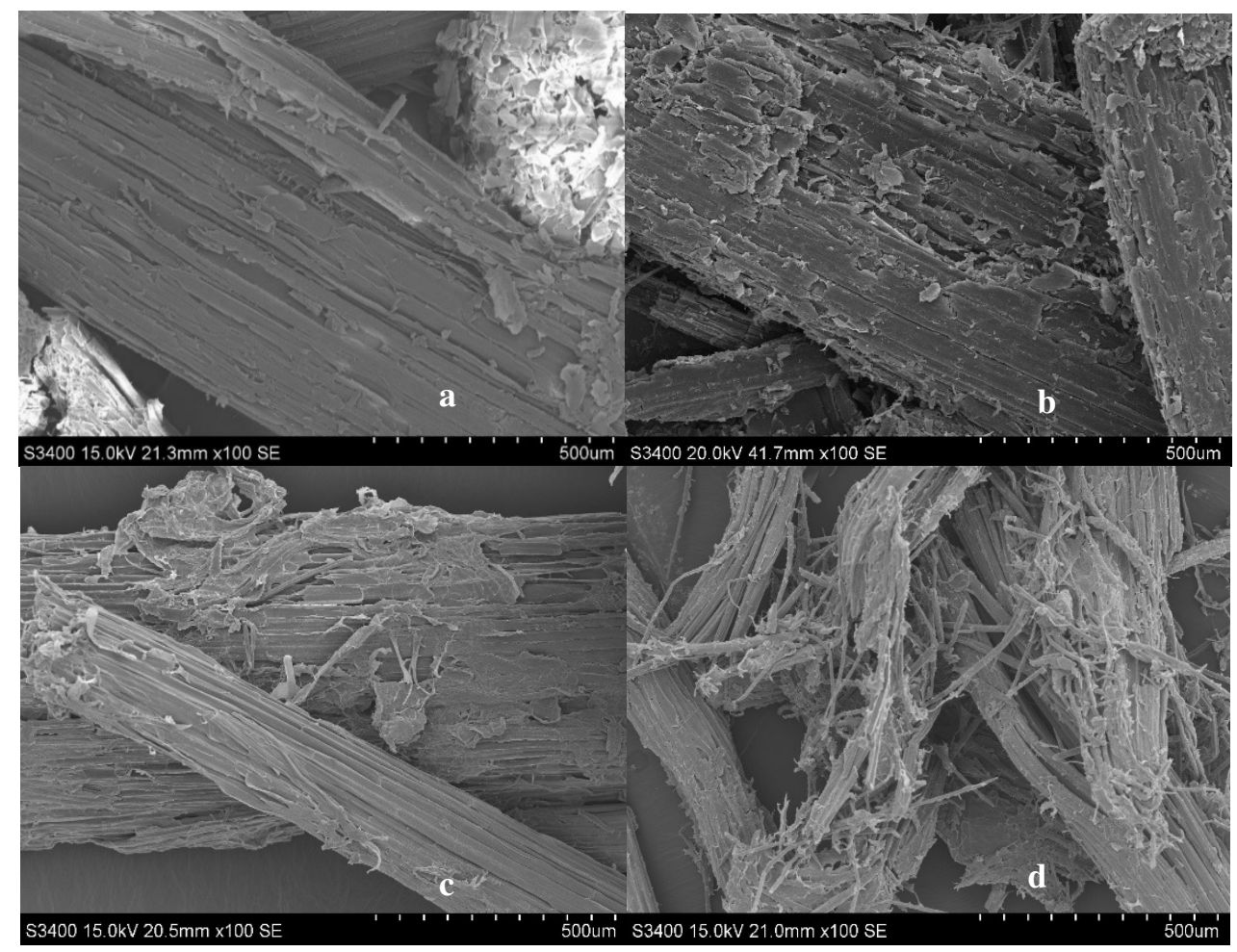

Figure 3: SEM analysis of sorghum biomass (a) before pretreatment, (b) after acidic pretreatment, (c) after alkaline pretreatment, (d) after enzymatic hydrolysis process 


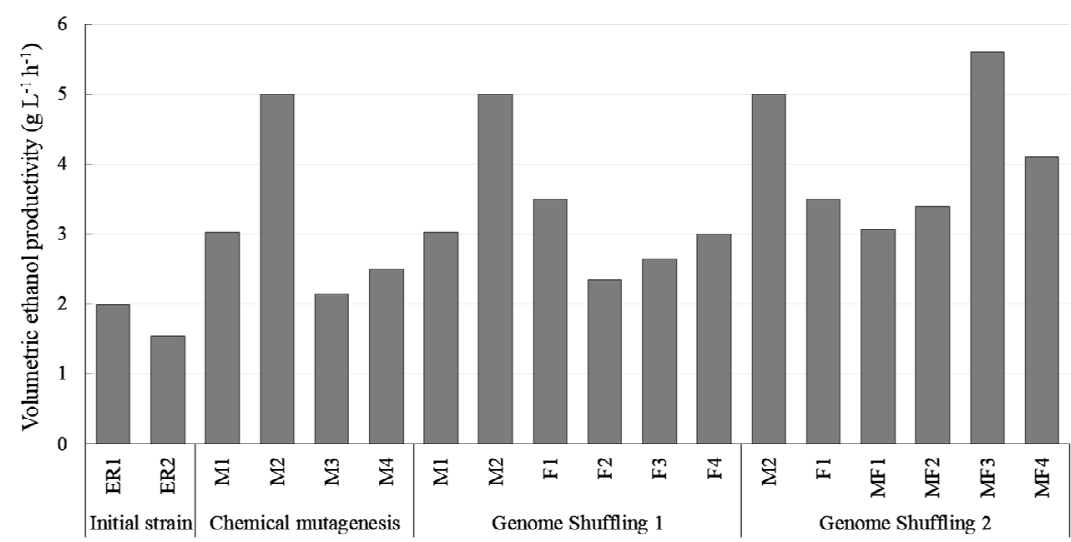

Figure 4: Ethanol productivity before and after genome shuffling (ER: initial strains; M: mutants; F: fusants after first round; MF: fusants after second round)

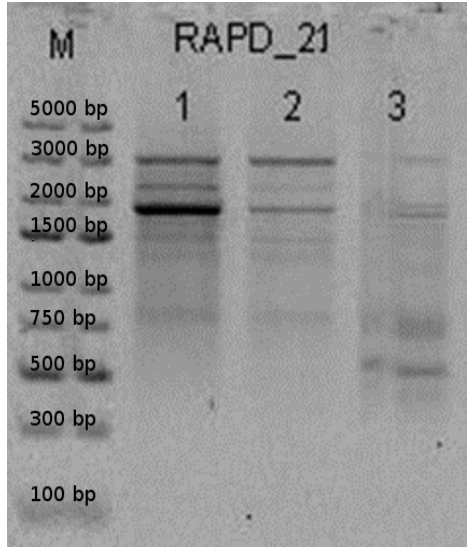

Figure 5: Polymorphism of genomic population by RAPD analysis (1, 2: parental strains; 3: fusant)

RAPD-PCR using the primer (Fig. 5) resulted in profiles different for the parental strains and the fusant. The separation of the profiles of DNA fragments primer allowed to conclude that at the length of 500 bp PCR products appeared, while the parental strains did not show bands at this level. In turn, between 3000 and 2000 bp in the fusant, no band was seen that was present in the profiles of the parental strains. When analysing the electrophoretic separation, it was observed that the selected fusants have genomic DNA fragments typical of both parental strains, which indicates that their genomes are shuffled.

The random amplification polymorphic DNA (RAPD) is a technique involving the use of any primers that attach to genomic DNA. This method detects genetic polymorphism, and, what is important, it does not require prior knowledge of sequences that are specific to a given species of strains. ${ }^{50}$ Therefore, the RAPD-PCR technique is often used to confirm the effectiveness of genome shuffling. ${ }^{51}$

\section{CONCLUSION}

It is suggested that sorghum biomass is a valuable feedstock for the production of ethanol due to its easy cultivation, favourable properties and high amounts of monosaccharides. The enzymatic hydrolysis of sorghum biomass can be significantly improved after a pretreatment with sodium hydroxide or sulfuric acid. However, the use of sodium hydroxide is a more efficient pretreatment method of sorghum biomass. The genome shuffling technique improves the phenotypic traits of Saccharomyces cerevisiae yeast, i.e. an increased fermentation activity, resistance to temperature, acidic and osmotic stress, making it possible to increase the efficiency of the production of bioethanol.

ACKNOWLEDGEMENT: The authors acknowledge the funding by the National Centre for Research and Development, Poland (Project No. PBS1/A8/9/2012). 


\section{REFERENCES}

1 H. N. Bhatti, M. A. Hanif, M. Qasim and Ata-urRehman., Fuel, 87, $2961 \quad$ (2008), https://doi.org/10.1016/j.fuel.2008.04.016

2 H. Burczyk, J. Kołodziej and M. Kowalska, Procs. The $13^{\text {th }}$ Science Conference of ISS\&PC-SRI, Puławy, Poland, 6-9.06.2009. pp. 7-8.

3 B. Śliwiński and F. Brzózka, Post. Nauk Rol., 1, 25 (2006).

4 R. Martín-Sampedro, J. L. Rahikainen, L. S. Johansson, K. Marjamaa, J. Laine et al., Biomacromolecules, 14, $1231 \quad$ (2013), https://doi.org/10.1021/bm400230s

5 S. Nakagame, R. P. Chandra and J. N. Saddler, Biotechnol. Bioeng., 105, $871 \quad$ (2010), https://doi.org/10.1002/bit.22626

6 N. Pareek, T. Gillgren and L. J. Jönsson, Bioresour. Technol., $\quad \mathbf{1 4 8 ,} \quad 70 \quad$ (2013), https://doi.org/10.1016/j.biortech.2013.08.121

7 Y. Pu, F. Hu, F. Huang, B. H. Davison and A. J. Ragauskas, Biotechnol. Biofuels, 6, 1 (2013), https://doi.org/10.1186/1754-6834-6-15

8 J. L. Rahikainen, R. Martin-Sampedro, H. Heikkinen, S. Rovio, K. Marjamaa et al., Bioresour. Technol, $\quad \mathbf{1 3 3}, \quad 270 \quad$ (2013), https://doi.org/10.1016/j.biortech.2013.01.075

9 A. Tejirian and F. Xu, Enzyme Microb. Technol., 48, 239 https://doi.org/10.1016/j.enzmictec.2010.11.004

10 A. T. W. M. Hendriks and G. Zeeman, Bioresour. Technol., $\quad \mathbf{1 0 0}, \quad 10 \quad$ (2009), https://doi.org/10.1016/j.biortech.2008.05.027

11 R. E. H. Sims, W. Mabee, J. N. Saddler and M. Taylor, Bioresour. Technol., 101, 1570 (2010), https://doi.org/10.1016/j.biortech.2009.11.046

12 P. Alvira, E. Tomas-Pejo, M. Ballesteros and M. J. Negro, Bioresour. Technol., 101, 4851 (2010), https://doi.org/10.1016/j.biortech.2009.11.093

13 R. P. Chandra, R. Bura, W. E. Mabee, A. Berlin, X. Pan et al., Adv. Biochem. Eng. Biotechnol., 108, 67 (2007), https://doi.org/10.1007/10_2007_064

14 A. T. Martínez, F. J. Ruiz-Dueñas, M. J. Martínez, J. C. del Río and A. Gutiérrez, Curr. Opin. Biotechnol., 20, $348 \quad$ (2009), https://doi.org/10.1016/j.copbio.2009.05.002

15 Z. Y. Yu, H. Jameel, H. M. Chang and S. Park, Bioresour. Technol., 102, $9083 \quad$ (2011), https://doi.org/10.1016/j.biortech.2011.07.001

16 M. J. Bussemaker and D. Zhang, Ind. Eng. Chem. Res., $\quad 52, \quad 3563 \quad$ (2013), https://doi.org/10.1021/ie3022785

17 Y. Sun and J. Cheng, Bioresour. Technol., 83, 1 (2002),

https://www.ncbi.nlm.nih.gov/pubmed/12058826

${ }_{18}$ M. Asgher, Z. Ahmad and H. M. N. Iqbal, Ind.

Crop. Prod., 44, 488 (2013), https://doi.org/10.1016/j.indcrop.2012.10.005

19 M. Balat, Energ. Convers. Manag., 52, 858 (2011), https://doi.org/10.1016/j.enconman.2010.08.013
20 W. Parawira and M. Tekere, Crit. Rev. Biotechnol., 31 , 20

(2011), https://doi.org/10.3109/07388551003757816

21 V. B. Agbor, N. Cicek, R. Sparling, A. Berlin and D. B. Levin, Biotechnol. Adv., 29, 675 (2011), https://doi.org/10.1016/j.biotechadv.2011.05.005

${ }^{22}$ H. A. Ruiz, D. P. Silva, D. S. Ruzene, L. F. Lima, A. A. Vicente et al., Fuel, 95, 528 (2012), https://doi.org/10.1016/j.fuel.2011.10.060

23 J. Choudhary, S. Singh and L. Nain, Electronic. $\begin{array}{llll}\text { Biotechnol., } & \text { 21, } & 82 & \text { (2016), }\end{array}$ https://doi.org/10.1016/j.ejbt.2016.02.007

24 L. J. Jönsson and C. Martín, Bioresour. Technol., 199 103

(2016),

https://doi.org/10.1016/j.biortech.2015.10.009

25 Y. Chen, L. Stabryla and N Wei, Appl. Environ. Microbiol., $\quad 82, \quad 2156 \quad$ (2016), https://doi.org/10.1128/AEM.03718-15

26 J. Gong, H. Zheng, Z. Wu, T. Chen and X. Zhao, Biotechnol. Adv., 27, $996 \quad$ (2009), https://doi.org/10.1016/j.biotechadv.2009.05.016

27 M. Wang, W. Zhang, W. Xu, Y. Shen and L. Du, Appl. Microbiol. Biotechnol., 100, 7491 (2016), https://doi.org/10.1007/s00253-016-7457-0

28 D. Biot-Pelletier and V. J. J. Martin, Appl. Microbiol. Biotechnol., 98, $3877 \quad$ (2014), https://doi.org/10.1007/s00253-014-5616-8

29 B. Adney and J. Baker, Technical Report NREL/TP-510-42628 (2008) https://www.nrel.gov/docs/gen/fy08/42628.pdf

30 T. K. Ghose and V. S. Bisaria, Pure Appl. Chem., 9, 1739 (1987), http://publications.iupac.org/pac/59/12/1739/index.htm 1

31 G. L. Miller, Anal. Chem., 31, 426 (1959), https://doi.org/0.1021/ac60147a030

32 TAPPI T13 m-54 Lignin in wood, https://www.tappi.org/

33 TAPPI T17 m-55 Cellulose in wood, https://www.tappi.org/

34 TAPPI T9 m-54 Holocellulose in wood, https://www.tappi.org/

${ }_{35}$ Y. Zheng, P. Zhongli and R. Zhang, Int. J. Agric. Biol. Eng., 2, 51 (2009), https://doi.org/10.3965/j.issn.1934-6344.2009.03.051068

36 D. Fengel and G. Wegener, "Wood. Chemistry, Ultrastructure, Reactions", Walter de Gruyter, BerlinNew York, 1985, https://doi.org/10.1002/pol.1985.130231112

37 R. T. Morrison and R. N. Boyd, "Organic Chemistry", PWN, Warszawa, 1985.

38 S. Prosiński, "Wood Chemistry", PWRiL, Warszawa, 1984

39 J. Batog, A. Wawro, D. Pieprzyk-Kokocha and Z. Skibniewski, Cellulose Chem. Technol., 50, 397 (2016), www.cellulosechemtechnol.ro/pdf/CCT34(2016)/p.397-400.pdf 
40 A. Goshadrou, K. Karimi and M. J. Taherzadeh, Materials of the World Renewable Energy Congress 2011, 8-13.05.2011, Linköping, Sweden, pp. 374-380 (2011),

http://www.ep.liu.se/ecp/057/vol1/050/ecp57vol1_050. pdf

S. Chang, W. Li and Y. Zhang, Carbon Resour. Convers., 1 , 147 (2018), https://doi.org/10.1016/j.crcon.2018.06.005

E. Corredor, P. S. Testillano, M. J. Coronado, P. González-Melendi, R. Fernández-Pacheco et al., BMC Plant Biol., 9, 45 (2009), https://doi.org/10.1186/14712229-9-45

43 D. J. Shi, C. L Wang and K. M. Wang, J. Ind. Microbiol. Biotechnol., 36, 139 (2009), https://doi.org/10.1007/s10295-008-0481-z

44 D. Q. Zheng, X. Ch. Wu, P.-M. Wang, X.-Q. Chi et al., J. Ind. Microbiol. Biotechnol., 38, 415 (2011), https://doi.org/10.1007/s10295-010-0784-8
45 K. Inokuma, R. Iwamoto, T. Bamba, T. Hasunuma and A. Kondo, Front. Bioeng. Biotechnol., 5, 1 (2017), https://doi.org/10.3389/fbioe.2017.00081

46 M. Sardi, V. Paithane, M. Place, D. Robinson, J. Hose et al., PLoS Genet., (2018), https://doi.org/10.1371/journal.pgen.1007217

47 Y. Lu, Y. F. Cheng, X. P. He, X. N. Guo and B. R. Zhang, J. Ind. Microbiol. Biotechnol., 39, 73 (2012), https://doi.org/10.1007/s10295-011-1001-0

${ }^{48}$ A. Tofighi, M. M. Assadi, M. H. A. Asadirad and S. Z. Karizi, J. Environ. Health Sci. Eng., 12, 107 (2014), https://doi.org/10.1186/2052-336X-12-107

${ }^{49}$ K. D. Jetti, R. Reddy, D. Garlapati and S. K. Nammi, Int. Microbiol., 22, 247 (2019), https://doi.org/10.1007/s10123-018-00044-2

50 W. Zhang and A. Geng, Biotechnol. Biofuels., 5, 46 (2012), https://doi.org/10.1186/1754-6834-5-46

51 J. Huang, D. Chen, Y. Wei, Q. Wang, Z. Li et al., The Scientific World Journal, ID 798683, (2014), https://doi.org/10.1155/2014/798683 